\title{
Evaluation of Stability of Serum on Different Storage Temperatures for Routine Chemistry Analytes
}

\author{
Byoungrak $\mathrm{An}^{1}$ and Chang-Eun Park $^{2}$ \\ ${ }^{1}$ Department of Laboratory Medicine, Yongin Severance Hospital, Yonsei University, Yongin 449-930, Korea \\ ${ }^{2}$ Department of Biomedical Laboratory Science, Namseoul University, Cheonan 331-707, Korea
}

\begin{abstract}
The stability of 21 routine biochemistry analytes was evaluated from the specimens which had been stored under three different temperature conditions for 30 days. Most of the 17 analytes showed significant change, however, the specimens under lower temperature showed more stability than those under higher temperature. Glucose, Albumin, $\gamma$-glutamyl transferase, HDL cholesterol analytes were stable over 30 days under $22^{\circ} \mathrm{C}, 4^{\circ} \mathrm{C}$, and $-66^{\circ} \mathrm{C}$ conditions. This study might be helpful in interpreting the results reflecting the rate of change when inadequate specimens are measured.
\end{abstract}

Keywords: Chemistry, Stability, Storage, Temperature

This is an Open Access article distributed under the terms of the Creative Commons Attribution Non-Commercial License (http://creativecommons.org/licenses/by-nc/3.0) which permits unrestricted non-commercial use, distribution, and reproduction in any medium, provided the original work is properly cited.

Copyright $(2014$ The Korean Society for Clinical Laboratory Science. All rights reserved,

\section{.}


Table 1. Analytes and analytical method

\begin{tabular}{lll}
\hline \multicolumn{1}{c}{ Analytes } & Unit & \\
\hline Calcium & $\mathrm{mg} / \mathrm{dL}$ & Methods \\
Phosphorus & $\mathrm{mg} / \mathrm{dL}$ & Cresolphthalein complexone \\
Glucose & $\mathrm{mg} / \mathrm{dL}$ & Phosphomolybdate, UV \\
BUN & $\mathrm{mg} / \mathrm{dL}$ & Hexokinase, UV \\
Creatinine & $\mathrm{mg} / \mathrm{dL}$ & Urease with GLDH (Coupled Enzymes) \\
Uric acid & $\mathrm{mg} / \mathrm{dL}$ & Kinetic alkaline picrate (Jaffe reation) \\
Cholesterol & $\mathrm{mg} / \mathrm{dL}$ & Uricase \\
Total protein & $\mathrm{g} / \mathrm{dL}$ & Enzymatic \\
Albumin & $\mathrm{g} / \mathrm{dL}$ & Biuret method \\
Alkaline phosphatase & $\mathrm{IU} / \mathrm{L}$ & Dye Binding-BCG \\
Total bilirubin & $\mathrm{mg} / \mathrm{dL}$ & PNPP, AMP buffer \\
AST & $\mathrm{IU} / \mathrm{L}$ & Diazonium salt/Diazonium ion with blank \\
ALT & $\mathrm{IU} / \mathrm{L}$ & UV without P5P \\
Latate dehyrogenase & $\mathrm{IU} / \mathrm{L}$ & UV without P5P \\
$\gamma$-glutamyl transferase & $\mathrm{IU} / \mathrm{L}$ & pyruvate to lactate \\
Triglycerides & $\mathrm{g} / \mathrm{dL}$ & G-glutamyl-carboxy-nitroanilide (IFCC, 37 ${ }^{\circ} \mathrm{C}$ ) \\
Sodium & $\mathrm{mmol} / \mathrm{L}$ & Enzymatic without glycerol blank without sample blank \\
Potassium & $\mathrm{mmol} / \mathrm{L}$ & ISE, diluted (indirect) \\
Chloride & $\mathrm{mmol} / \mathrm{L}$ & ISE, diluted (indirect) \\
HDL cholesterol & $\mathrm{mg} / \mathrm{dL}$ & ISE, diluted (indirect) \\
LDL cholesterol & $\mathrm{mg} / \mathrm{dL}$ & Enzymatic Immunoinhibition \\
\hline
\end{tabular}

The measured by chemistry analyzer with Olympus AU2700 (Beckman Coulter, Tokyo, Japan).

\section{Statistical Analysis}

The changing rate from the initial baseline values was shown in the Levy-Jennings chart. ACL was determined by bi-directional changes based on coefficient of variation (CV), which has the $95 \%$ of confidence interval values shown as ISO 5725-6 (ISO, 1994). The CV was obtained from internal quality control values, which had been accumulated for over six months. When the results for an analyte were beyond the limit, they were judged as they had significance, that is, they were the unstable samples.

\section{Results}

Stability of individual analyte in pool serum showed various patterns on different periods of time and temperatures shown in Fig. 1. Analytes, of which result values had increased, tended to show far more increased values as specimen were stored under higher temperatures (Fig. 1A). Analytes, whose result values had decreased, tended to be more stable than those at $22^{\circ} \mathrm{C}$ condition as specimens were stored under lower temperatures. ALP, which showed more or less decreased, were somewhat flexible in temperature conditions. $\mathrm{LDH}$ seemed to be stable at $-66^{\circ} \mathrm{C}$, but more unstable at $4^{\circ} \mathrm{C}$ than at $22^{\circ} \mathrm{C}$ (Fig. 1B).

Most of the 12 analytes such as phosphorus, triglyceride, calcium, BUN, cholesterol, potassium, chloride, creatinine, uric acid, sodium, LDL cholesterol, and total protein increased after 3 to 5 days when stored at $22^{\circ} \mathrm{C}$ temperature condition. Only 3 analytes such as phosphorus, triglyceride, and calcium were decreased after 23 to 29 days when stored at $4^{\circ} \mathrm{C}$ condition, however, the rest of the analytes were stable for over 30 days at $-66^{\circ} \mathrm{C}$ condition (Table 2).

Five analytes such as total bilirubin, ALT, AST, alkaline phosphatase, and latate dehyrogenase were decreased after 1 to 26 days when stored $22^{\circ} \mathrm{C}$ condition. Pool serum decreased after 1 to 12 days at $4^{\circ} \mathrm{C}$ condition. Only AST and ALT analytes stable at $-66^{\circ} \mathrm{C}$ condition. Four analytes such as glucose, albumin, $\gamma$-glutamyl transferase, and HDL cholesterol were stable during the whole test period at all temperatures (Fig. 1C).

\section{Discussion}

In laboratory, samples are rerun after the initial tests are completed, or go through additional tests when necessary. 


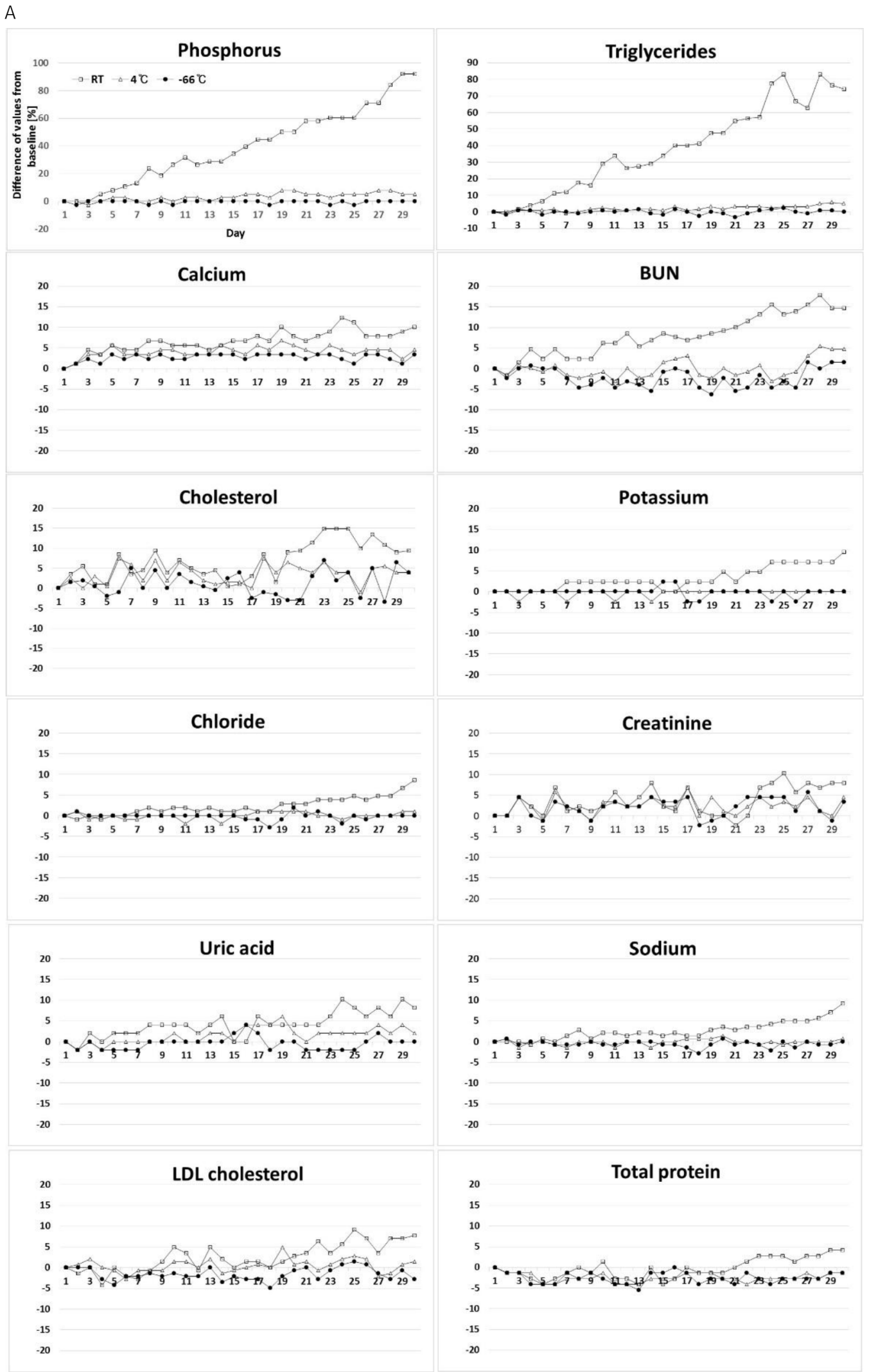

Fig. 1. Stability of routine chemistry analytes according to different time and temperature condition for 30 days. Square, room temperature; triangle, $4^{\circ} \mathrm{C}$; circle, $-66^{\circ} \mathrm{C}$. (A) Increased analytes. (B) Decreased analytes. (C) Stable analytes. 


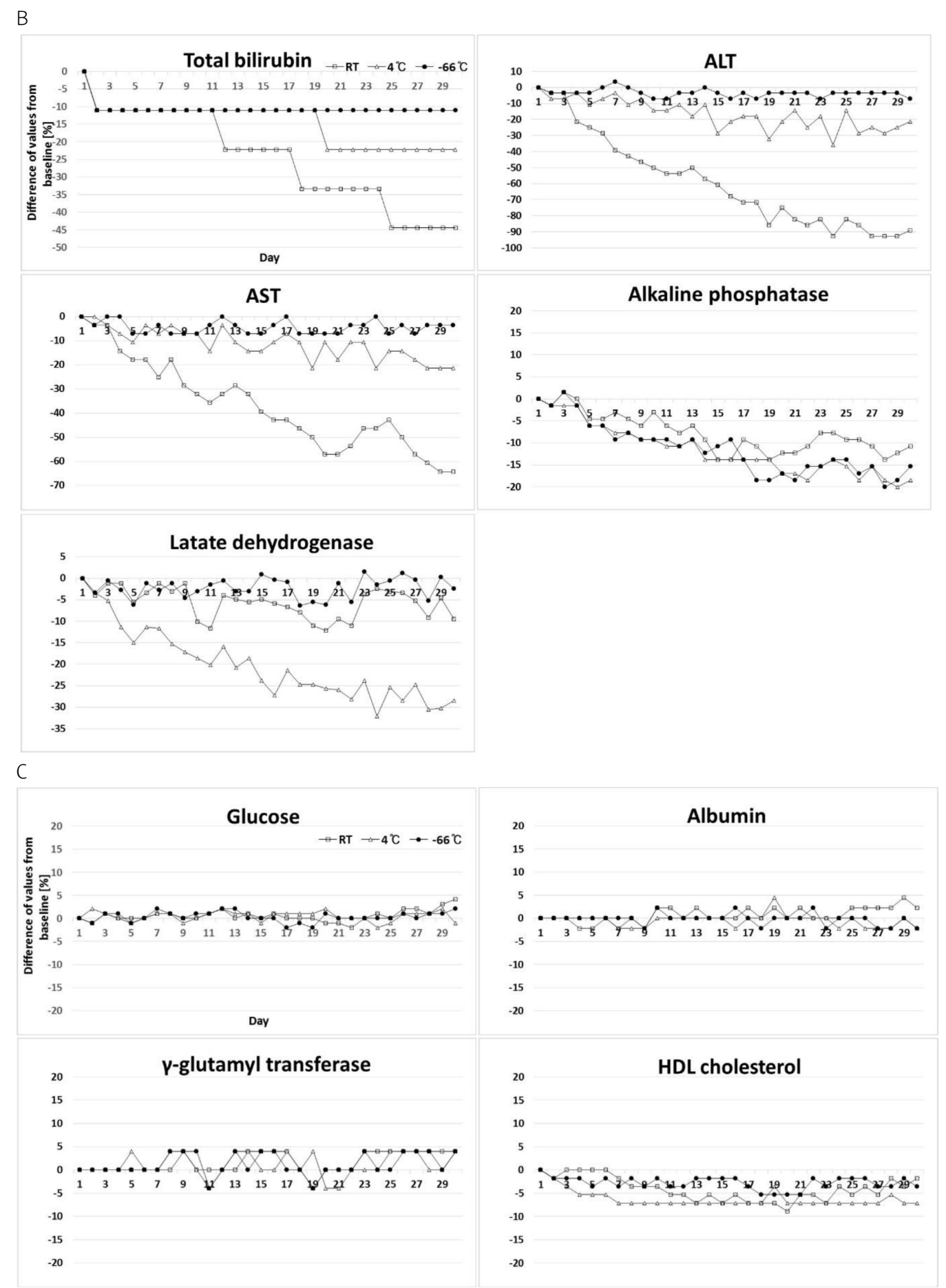

Fig. 1. Continued.

The results might be affected by the storage and time conditions or test reagent. In this study, the stability of the 21 common chemistry analytes shown in Table 1 was evaluated according to different temperature conditions.

When samples were stored at room temperature, phosphorus, triglyceride, calcium, BUN, cholesterol, potassium, chloride, creatinine, uric acid, sodium, LDL cholesterol and total protein increased at a consistent rate with the lapse of time, and changing range from the baseline values decreased at a low temperature. In particular, 
Table 2. Stability of routine chemistry analytes in acceptable changes limit

\begin{tabular}{|c|c|c|c|c|c|}
\hline \multirow{2}{*}{ Analytes } & \multirow{2}{*}{ Baseline values } & \multirow{2}{*}{$\mathrm{CV} \%\left(\mathrm{ACL}^{*}\right)$} & \multicolumn{3}{|c|}{ Out of range after days* } \\
\hline & & & $22^{\circ} \mathrm{C}$ & $4^{\circ} \mathrm{C}$ & $-66^{\circ} \mathrm{C}$ \\
\hline Phosphorus & 3.8 & $1.72(3.7 \sim 3.9)$ & $3 \Delta$ & $23 \boldsymbol{\Delta}$ & - \\
\hline Triglycerides & 124 & $1.53(120 \sim 128)$ & $3 \boldsymbol{\Delta}$ & $27 \boldsymbol{A}$ & - \\
\hline Calcium & 8.9 & $1.59(8.6 \sim 9.2)$ & $4 \Delta$ & $29 \boldsymbol{\Delta}$ & - \\
\hline BUN & 12.9 & $2.48(12.3 \sim 13.5)$ & $9 \boldsymbol{\Delta}$ & - & - \\
\hline Cholesterol & 202 & $3.11(189 \sim 215)$ & $19 \boldsymbol{\Delta}$ & - & - \\
\hline Potassium & 4.2 & $1.54(4.1 \sim 4.3)$ & $21 \boldsymbol{\Delta}$ & - & - \\
\hline Chloride & 105 & $1.4(102 \sim 108)$ & $21 \boldsymbol{\Delta}$ & - & - \\
\hline Creatinine & 0.88 & $2.16(0.84 \sim 0.92)$ & $22 \boldsymbol{A}$ & - & - \\
\hline Uric acid & 4.9 & $1.55(4.7 \sim 5.1)$ & $22 \boldsymbol{\Delta}$ & - & - \\
\hline Sodium & 141 & $1.7(136 \sim 146)$ & $23 \boldsymbol{\Delta}$ & - & - \\
\hline LDL cholesterol & 142 & $2.69(134 \sim 150)$ & $24 \Delta$ & - & - \\
\hline Total protein & 7.3 & $1.63(7.1 \sim 7.5)$ & $28 \boldsymbol{\Delta}$ & - & - \\
\hline Total bilirubin & 0.9 & $2(0.9 \sim 0.9)$ & $1 \nabla$ & $1 \nabla$ & $1 \nabla$ \\
\hline ALT & 28 & $2.59(27 \sim 29)$ & $3 \nabla$ & $7 \nabla$ & $29 \nabla$ \\
\hline AST & 28 & $2.44(27 \sim 29)$ & $3 \nabla$ & $12 \nabla$ & - \\
\hline Alkaline phosphatase & 65 & $3.14(61 \sim 69)$ & $13 \nabla$ & $6 \nabla$ & $6 \nabla$ \\
\hline Latate dehyrogenase & 327 & $3.53(304 \sim 350)$ & $26 \nabla$ & $2 \nabla$ & - \\
\hline Glucose & 97 & $1.58(94 \sim 100)$ & - & - & - \\
\hline Albumin & 4.5 & $1.74(4.3 \sim 4.7)$ & - & - & - \\
\hline$\gamma$-glutamyl transferase & 25 & $2.05(24 \sim 26)$ & - & - & - \\
\hline HDL cholesterol & 56 & $3.19(52 \sim 60)$ & - & - & - \\
\hline
\end{tabular}

$\boldsymbol{\Delta} \boldsymbol{\nabla}$, increase or decrease. *Acceptable change limit was determined by the $95 \%$ of confidence interval value for bi-directional changes base on coefficient of variation by ISO 5725-6. (ISO, 1994).

phosphorus, triglyceride and creatinine increased abruptly at room temperature. However, most of the analytes showed stable results in the frozen condition of $-66^{\circ} \mathrm{C}$ for up to over 30 days.

In previous studies, phosphorus, triglyceride, total bilirubin, ALT and AST have been reported unstable at room temperature for 1 3 days (Ehret et al, 2002), but calcium, creatinine and uric acid have been reported stable at $-20^{\circ} \mathrm{C}$ up to 4 months (Wilson et al, 1972; Donnelly et al, 1995). We think that the increased result values in a metabolite group is probably caused by evaporation. Accordingly, a frozen condition or sealing the tubes is recommended for long term storage if possible.

The total bilirubin, ALT, AST, alkaline phosphatase and latate dehyrogenase level decrease consistently with the lapse of sample storage time. The changing rate decreases as the temperature gets lower, but time is considered more influential than the temperature. Alkaline phosphatase was less affected by the temperature conditions. Especially, Latate dehyrogenase is more unstable in the frozen condition than at room temperature, which is more evident in the enzyme group. In previous studies, total bilirubin, ALT, and alkaline phosphatasehas been reported unstable at room temperature (Hwang et al, 2002).

Glucose, albumin, $\gamma$-glutamyl transferase, HDL and cholesterol were evaluated to be within the acceptable change limits in all the conditions for 30 days. These tests seem stable if they are prevented from being evaporated after being separated as the serum. LDL cholesterol and HDL cholesterol were confirmed more stable for about one month (23 30 days) compared with the data that were resulted within 1 2 days at room temperature in the previous study (Ehret et al, 2002). In the previous study, glucose and uric acid analytes decreased under room temperature and refrigerator condition (Ahmed MD et al, 2010). However, in our study, glucose did not show any distinguishable changes when serum was separated and uric acid increased, which means we need to consider specimen sealing, collection tubes, storage temperature changes, and specific possible factors in each laboratory.

When the results from the samples in different storage conditions and time are analyzed, they need to be interpreted 
according to Fig. 1. The results of this study may be very helpful for the accurate interpretation of clinical reports and determining the sample storage period in laboratories.

\section{Acknowledgements: None}

Funding: None

Conflict of interest: None

\section{References}

1. Ahmed MD, Daleel AA Kamal EA. Effect of storage time and temperature on some serum analytes. International Journal of Pathology. 2010, 8:68-71.

2. Boyanton BL, Blick KE. Stability studies of twenty-four analytes in human plasma and serum. Clin Chem. 2002, 48:2242-7.

3. Clinical and Laboratory Standards Institute (CLSI). Procedures for the handling and processing of blood specimens for common laboratory tests; approved guideline. Document H18-A4,
Vol. $30 \mathrm{~N}^{\circ} 10 ; 2010$.

4. Donnelly JG, Soldin SJ, Nealon DA, Hicks JM. Stability of twenty-five analytes in human serum at 22 degrees C, 4 degrees C, and 220 degrees C. Pediatr Pathol Lab Med. 1995, 15:869-74.

5. Ehret W, Heil W, Schmitt Y, Töpfer G, Wisser H, Zawta B, et al. Use of anticoagulants in diagnostic laboratory investigations and stability of blood, plasma and serum samples. WHO/DIL/LAB/99.1 Rev 2; 2002.

6. Ellis MJ, Livesey JH, Evans MJ. Hormone stability in human whole blood. Clin Biochem. 2003, 36:109-12.

7. Evans MJ, Livesey JH, Ellis MJ, Yandle TG. Effect of anticoagulants and storage temperatures on stability of plasma and serum hormones. Clin Biochem. 2001, 34:107-12.

8. Hwang SY, Kim JS, Choo SK, Kim IT, Chang CS. Evalution of Stability of Quality Control Materials used in Clinical Chemistry Tests. Korean J Clin Lab Sci. 2000, 32:177-186

9. ISO 5725-6. Accuracy (trueness and precision) of measurement methods and results. Part 6: use in practice of accuracy values; 1994.

10. Wilson SS, Guillan RA, Hocker EV. Studies of the stability of 18 chemical constituents of human serum. Clin Chem. 1972, 18:1498-503. 